\title{
Godsdiens het die politiek nodig en die politiek is weer- loos daarsonder
}

J H le Roux

(UP)

\section{ABSTRACT}

\section{Religion needs politics and politics is powerless without it}

In 1996 Karel van der Toorn published a very important book on family religion in Babylonia, Syria and Israel. He introduced us to the very exciting world of ancient man and his religion. This article stresses the importance of a history of religions approach. It furthermore focusses on the close link between religion and politics. Israel's religion was moulded and shaped by socio-economic powers; it was used by statesmen to support their political endeavours. Yahweh religion is thus the result of specific social powers which formed it in a specific era in Israel's history.

In 1996 het 'n belangrike werk van Karel van der Toorn oor familie-

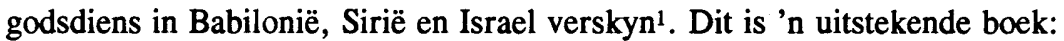
geleerd, kennisryk, deeglik nagevors, volledig, leersaam en lekker om te lees. Vanweë die swak Suid-Afrikaanse geldeenheid sal hierdie boek egter nie maklik aangeskaf kan word nie. Dit is eenvoudig te duur. Dit is jammer, want Van der Toorn het 'n belangrike venster op die daaglikse godsdiensbeoefening van die Ou-Nabye-Oosterse mens oopgemaak. Veral grieselrig is die lang en deeglike gedeeltes oor die voorvaders. Alhoewel die dooies tot die gebied van die gode behoort, leef hulle as 't ware in die gemeenskap van die lewendes voort. Hulle word ook op 'n stillerige plek in die huis begrawe en daagliks moes sekere rites vervul word. Elke maand met die "interlunium" is daar 'n fees, waartydens allerlei heerlikhede verorber is, gevier. Daa is elke jaar 'n soort "All souls Day" gehou. Geweldig baie inligting word in verband met die plek waar die dooies begrawe is, die gesag van die voorvaders, die verering van die voorvaders, die gode en 'n wiegeliedjie om die geeste te kalmeer, verstrek.

Van der Toorn het Israel (veral die noordelike bewoners van die land) binne hierdie Ou-Nabye-Oosterse konteks geplaas. Hulle was maar soos alle ander antieke mense. Hulle het ook familiegode geken en die voorvaders vereer: "In the early Israelite culture where individual clan settlements enjoyed a great deal of independence, the ancestor cult is bound to have played a major role in the day-to-day religion" 2 . In die $\mathrm{Ou}$ 
Testament was dit egter 'n verborge tradisie: "The Israelite cult of the dead is in many ways a hidden heritage - hidden because deleted from, or at least disguised and obfuscated in, the written records" 3 . Uit Van der Toorn se werk blyk die lang en komplekse ontwikkeling van Israel se geloof. Vanaf die aanbidding van familiegode, die verering van die voorvaders tot die Noordryk se Jahwe-geloof was 'n moeisame weg. In dié proses het die politiek Israel se godsdiens geslyp en die godsdiens was 'n handige staatsinstrument. 'n Noue band bestaan dus tussen godsdiens en politiek (in die sin van sosio-ekonomiese kragte). Hierdie brose verhouding word in dié artikel belig. Belangrik is dat Van der Toorn dit binne 'n historiese raamwerk geplaas het. Wanneer 'n mens ons tema histories verstaan, begryp jy net soveel meer: denke en konteks vloei saam, mens en godsdiens kry nuwe dimensies, ontstaan en ontwikkeling van 'n teologie word duideliker, godsdiens en politiek word 'n hegte eenheid. Daarom eers iets oor die belang van godsdiensgeskiedenis.

\section{GESKIEDENIS HELP ONS OM MENSE TE VERSTAAN}

Van der Toorn se werk beklemtoon opnuut die moontlikhede en waarde van 'n godsdiensgeskiedenis. 'n Historiese bemoeienis met Israel se verlede is belangrik, want dit bring ons uiteindelik by mense. Gewone mense wat op verskillende maniere met God en die wêreld geworstel het. Deur die geskiedenis verstaan ons die noue band tussen godsdiens en politiek. Van geskiedenis kan ons tog nie genoeg maak nie. Ons het geskiedenis nodig om Afrika en ons plek daarin te verstaan. Ons moet histories dink sodat ons sin aan die lewe kan gee. Indien ons histories wil werk, is Van der Toorn 'n goeie gids. In die lig van ons eie situasie en navorsingsgeskiedenis moet ons die volgende onthou:

Godsdiensgeskiedenis moet weer deel van die kurrikulum word4. 'n Godsdienshistoriese benadering kan die wêreld waarin die Ou Testament ontstaan, blootlê; die lewende konteks waarin Israel se teologieë gevorm is, belig; die omstandighede waarin Israel se geloof voortdurend geïnterpreteer en geherinterpreteer is, beskryf ${ }^{5}$. Kortom: "Religionsgeschichte Israels, das ist keine blutleere Ideengeschichte, sondern ein lebendiger Prozess ständiger Auseinandersetzung, ein dauerndes Streitgespräch unterschiedlicher Gruppen der israelitischen Gesellschaft"6. Dít het Van der Toorn se godsdiensgeskiedenis aangetoon en dít maak sy werk uiters belangrik.

'n Godsdiensgeskiedenis van Israel is wel moontlik. Te dikwels word gemeen dat die antieke tekste te min historiese feite verskaf. Een 
rede vir hierdie beperkende siening is die mening dat taal die enigste toegang tot die historiese werklikheid verleen; dat ons slegs deur taal (sinkronies dus!) onproblematies die vergange werklikheid kan betree. En indien taal nie die feite oplewer nie, is kennis van die verlede ondenkbaar? Van der Toorn het juis die teendeel bewys: kennis van Israel is moontlik al hou die taal (die teks) belangrike "feite" terug.

'n Godsdiensgeskiedenis impliseer nie primêr die metodiese ontsluiting van feite nie. Die boustof vir die geskiedenis is nie "die korrekte metode" nie, maar die navorser se ervaringe. Dít is beslissend vir enige geskiedenis: "Now the historian is a man with an experience of his own ... and it is this experience which he brings with him to the interpretation of historical evidence ... This experience tells him what kind of things can happen; and this is the canon by which he criticizes testimony" 8 . Aggressiewe inlees van die eie ervaringe in die teks bring 'n godsdiensgeskiedenis tot stand.

Daar word in 'n godsdiensgeskiedenis moeite gemaak met die geworde en nie soseer die gestolde teks nie. Sonder kennis van die geworde teks is 'n geskiedenis nie moontlik nie. Van der Toorn moes die nate in die teks raaksien, die verskillende teks(gedeeltes) dateer, moontlike ontstaanskontekste maak, moontlike skrywer(s) identifiseer, die historiese gang van die godsdiens beskryf, die godsdienshistoriese ontwikkelinge en veranderinge aantoon, ensovoorts. Dit kon slegs omdat hy die geworde teks met erns bejeën het.

'n Godsdiensgeskiedenis van Israel is 'n riskante en selfs 'n futiele onderneming. Nooit kan ons hier en nou direkte toegang tot die gebeure van Israel se geskiedenis verkry nie. Al wat die gebeure agtergelaat het, is "spore, die merke of tekens wat die gebeure in haar vlugtog voor die denke uit agter(ge)laat" het ${ }^{9}$. Wie dus met Israel se verlede besig is, werk met historiese brokstukke ${ }^{10}$. In die teks is slegs spatsels van die verlede, dowwe spore wat na 'n konteks kan lei en naklanke waarna fyn geluister moet word. En dit is juis die uitdaging vir die Ou Testamentikus (historikus): hy/sy moet spoor kan sny, spatsels kan sien en dowwe klanke kan hoor. Om dit te kan doen, is kuns. Hierin het Van der Toorn uitnemend geslaag. Op 'n verrassende wyse het hy geluister, moontlike leidrade opgevolg en 'n verhaal gemaak.

\section{GODSDIENS IS HISTORIES-BEPAALD}

Van der Toorn kon dalk meer teoreties oor die verhouding godsdiens en samelewing besin het. Dit was nie sy bedoeling nie en daarom is hierdie 
kritiekpunt onvanpas. Sy werk spoor egter tot sodanige denke aan. Van der Toorn se beskrywing van die familiegodsdiens het 'n mens opnuut oor die verhouding godsdiens en gemeenskap, religie en politiek asook die wedersydse beïnvloeding laat dink. Is godsdiens die produk van 'n bepaalde samelewing en kan dit ooit die sosio-ekonomiese kragte van 'n gemeenskap ontsnap? Hieronder word dié kritiese verhouding met behulp van Van der Toorn se insigte belig. Vooraf eers die volgende:

Godsdiens vorm 'n integrale deel van die samelewing. Van die antieke gemeenskap was dit in besonder waar. Godsdiens was allesbepalend. ' $n$ Gewone burger se daaglikse lewe was omgeef met godsdiens: die gode moes met erns bejeën word, die teenwoordigheid van die voorvaders was 'n werklikheid, sekere dae was heilig, maaltye van 'n religieuse aard moes met die familie geniet word, ensovoorts. Dag vir dag is die lewe deur godsdiens bepaal en met godsdiensrites aan die voorvaders en die gode gevul.

Godsdiens het inderdaad ook die gemeenskap gevorm, maar is ook radikaal deur die samelewing gevorm, geslyp en verander. Wie jy was, is deur die kleinsamelewing bepaal: waar jy gebore is, het jou identiteit gevorm; wie jou god was, is deur jou pa en oupa bepaal. Godsdiens se druk is terdeë gevoel en die samelewing het jou "gemaak". Beweegruimte was uiters skraal. Keuses was maar min. Veral is die keuse ten opsigte van die tipe godsdiens en die aard van die god wat aanbid is vooraf vir jou geneem. 'n Mens is inderdaad in 'n bepaalde godsdiens wat deur ' $n$ bepaalde samelewing gevorm is, gewerp.

Godsdiens (die uiterlike vorm in elk geval) is die produk van sosioekonomiese kragte in die samelewing. Inderdaad is dit ook van die Jahwegeloof waar. Dat Jahwe uiteindelik die God van Israel geword het, is deur sekere sosio-historiese kragte bepaal. Saul het iets gedoen, met geweldige gevolge, Jerobeam I en die Omriede se godsdienspolitiek het die Jahwegeloof ingrypend verander. Hierdie punt is so belangrik dat ons dit weer herhaal.

Godsdiens kan nie los van gemeenskapskragte soos magspolitiek, ekonomiese beleid, sosiale oortuigings en militêre optrede gesien word nie. Anders gestel: Israel se godsdiens het uit die smeltkroes van die geskiedenis gegroei; dit is deur sekere definitiewe sosiale kragte geslyp en gevorm. Kortom: Israel se godsdiens is die produk van 'n bepaalde tyd; wat ons in die Ou Testament het, is die resultaat van 'n lang proses; dat alles so en nie anders lyk nie, is vanweë sekere spesifieke gemeenskapkragte en politieke ontwikkelings. Indien ander omstandighede gegeld het, het dinge anders gelyk. 
Godsdiens benodig ook klaarblyklik die politiek. Belangrike teologiese gesigspunte kon slegs met behulp van die staat ontstaan en voortbestaan het. Die Noordryk se Jahwe-geloof is ook positief deur sosiopolitieke kragte (al was dit ook negatief!) gevorm. Dalk sou die uittogverhaal, die rol van Moses, die ontstaan van die Jahwe-El-geloof, ensovoorts, nooit sonder die selfsugtige politieke motiewe van die konings ontstaan en kragtig ontwikkel het nie.

\section{FAMILIE EN FAMILIEGODE}

Teen die tiende eeu voor Christus het Saul iets gedoen met geweldige konsekwensies: hy het Jahwe die alleen-God van die staat gemaak. Die gevolge van sy besluit word tot vandag toe gevoel. Jahwe het nie altyd hierdie posisie beklee nie; Hy het dit vanweë sosio-politieke redes geword. Om dit te begryp, moet ons eers die familie en die familiegode verstaan.

Israel het nie eintlik van sy bure verskil nie. Die familie was die kleinste sosiale eenheid en het uit 'n groot aantal mense bestaan: pa en ma, alle getroude manskinders met hulle gesinne, ongetroude kinders, ongetroude broers of susters van die pa asook ander lede van voorgeslagte. Alle familielede het saam 'n hegte eenheid gevorm. Hulle was op mekaar aangewese, maar ook heeltemal selfversorgend. Gewoonlik het die familiehoof die leiding geneem: onderlinge onenigheid het hy besleg, by begrafnisse het hy die voortou geneem, as losser opgetree, ensovoorts. Familielede was in 'n seker sin vasgevang: hulle was aan die gemeenskap en die streek uitgelewer, hulle kon nie eintlik hulle horisonne verbreed nie en hulle is deur die kleingroep gedefineer ${ }^{11}$.

Wat godsdiens betref, was die Israelitiese familie uit die tyd voor die konings soos alle ander Ou-Nabye-Oosterse families. Daar was huisgode en daar was voorvadergeeste en voorvaderverering. Elke familie het die god van die familie aanbid en was van die voorvaders bewus. Alhoewel die skrywers van die Ou Testament dit probeer verdoesel het, is die naklanke net te sterk. Israel het geweet van die voorvadergeeste: hulle was omring van mense wat die voorvaders in die huis begrawe het, offers aan hulle gebring het, formules oor hulle uitgespreek het en gemeen het die voorvaders is nog steeds teenwoordig. Hierdie praktyk is mettertyd met wortel en tak uit Israel uitgeroei ${ }^{12}$.

Israel het ook familiegode geken. 'n Eenvoudige kultusplek is opgerig en 'n eenvoudige ritueel onder leiding van die familiehoof het plaasgevind ${ }^{13}$. Interessant is dat in die gebiede Efraim, Manasse en Benjamin, die kern van die latere Noordryk, Jahwe nie almal se familiegod was nie. Dit blyk uit die volgende: 
* 'n Studie van teofore name uit die vóór-koningstyd vertoon iets van die spiritualiteit van Efraim, Manasse en Benjamin ${ }^{14}$. Van die drie en dertig teofore name uit bogenoemde stamme blyk dat slegs sewe na Jahwe verwys. Sestien name bevat "El" en tien "Baäl" en ander godename. Klaarblyklik het die aanbidding van Jahwe nie so wydverspreid voorgekom nie: "In the period up to David El appears to have been a more popular element in theophoric personal names than YHWH"15. Meeste Israeliete het die god El en ook Baäl aanbid. Jahwe-aanbidders was dalk in die minderheid: "(T)he worship of Yahweh ... was the religion of the minority of the population ... the important groups of the early Israelites worshipped the gods $\mathrm{El}$ and Baal"16.

* Teofore plekname uit bogenoemde streke bevat hoofsaaklik die name van Kanaänitiese gode. Interessant is die afwesigheid van Jahwe: "The complete absence of the name Yahweh from the Early Iron Age toponyms is striking. Since theological considerations fail to explain this fact, it must be taken as a reflection of the relative unimportance of the worship of Yahweh among the early Israelites"17.

* Die sogenaamde Elohis ondersteun hierdie toedrag van sake ${ }^{18}$. In die Noordryk gedurende $825-725 \mathrm{vC}$ is $\mathrm{El}$ aanbid. Dit blyk ook uit enkele plekname: Bet-El ("Huis van El" Gen 28:18-22), Pniël ("Aangesig van El" Gen 32:31); 'n altaar wat Jakob "El-is-die-God-van-Israel" (Gen 33:20) noem; die altaar by Bet-El is "El-Bet-El" genoem (Gen 35:7). El is veral aan die familie gebind. Abraham, Isak en Jakob het $\mathrm{El}$ aanbid en dit was vir die hele familiegroep beslissend. Almal moes El aanbid. Bloedverwantskap het bepaal dat El aanbid sou word: "As argued ... the patriarchal narratives ... suggest that the family religion of many Israelites before the monarchy was focused on $\mathrm{El}^{\prime 19}$.

\section{JAHWE KOM VAN DIE SUIDE}

Voor die koningstyd was die aanbidding van Jahwe nie so algemeen in die noordelike heuwellande nie. Vir die mense van die noorde was $\mathrm{El}$ en ook Baäl belangrik. Dit het van familie tot familie gewissel. Op 'n sekere tydstip voor die instelling van die monargie het Jahwe as 't ware in die noorde gekom. Hoe het dit gebeur? Klaarblyklik vanweë sosio-ekonomiese redes.

In die Ou Testament is daar 'n sterk tradisie wat Jahwe aan die suide en meer bepaald Edom verbind. In sommige teofanietekste kom Jahwe uit 
Seïr, die velde van Edom (Rig 5:4). Volgens Deuteronomium 33:2 kom Hy van Sinai af en "Hy laat van Seïr af sy lig oor sy volk skyn, laat dit deurbreek van Paranberg af". Habakuk vertel weer dat Hy van Teman en Paran kom (3:3). Al hierdie plekke (Seïr, Paranberg, Teman en Sinai) was in Edom geleë. Hierdie suidelike en Edomitiese lokalisering van Jahwe word moontlik selfs deur Egiptiese tekste uit die veertiende en die dertiende eeu ondersteun. In hierdie tekste word na "Yahu in die land van die Sosu-bedoeienes" verwys. Heelwaarskynlik was hierdie land in die gebied van Edom en Midian geleë20.

Hoe het Jahwe dan in die noorde van die land gekom? Aanloklik bly nog steeds die tradisionele Kenitiese teorie ${ }^{21}$ : Moses se skoonpa was 'n Kenitiese priester, by die Keniete het hy van Jahwe gehoor en dit weer aan Israel vertel. Van der Toorn gebruik hierdie teorie slegs gedeeltelik: Israel het wel by die Keniete van Jahwe gehoor, maar dit is nie deur Moses bemiddel nie. Hoe het dit dan gebeur? Deur handelaars! Van vroegs af was Kenitiese handelaars reeds in die noorde werksaam. Volgens Genesis 37:28 was Midianitiese handelaars tussen Palestina en Egipte doenig. Kortom: Jahwe was 'n suidelike god wat deur handelaars se toedoen in die noorde bekend geword het ${ }^{22}$.

\section{SAUL VOER DIT VERDER}

Saul was die eerste koning en het die samelewing radikaal verander: 'n permanente leer, 'n groot amptenary, belastings, ensovoorts, is ingestel. Ewe radikaal was sy godsdiensbeleid: Jahwe sou die nasionale God van die nuwe staat wees. Hoe het dit gebeur? Saul was 'n Gibeoniet en hulle het sterk bande met die Edomiete gehad. Dit blyk onder andere uit die ooreenkoms tussen Gibeonitiese en Edomitiese name: Saul het dieselfde naam as 'n Edomitiese koning (Gen 36:37,38) gehad; Aja, die skoonpa van Saul (2 Sam 3:7; 21:8,10,11) is ook die naam van die seun van Sibon, 'n seun van Seïr (Gen 36:24; 1 Kron 1:40); Jeüs, 'n afstammeling van Saul (1 Kron 8:39) is ook die naam van 'n seun van Esau (Gen 36:5,14,18; 1 Kron $1: 35$ ). Uit hierdie en ander name blyk "that both the Gibeonites and the Saulides belonged to a strain represented also among the early Edomites"23.

Die res is eenvoudig: Saul, die Gibeoniet, en sy familie se noue bande met die suide, veral die Edomiete, het hulle band met Jahwe verstewig. Jahwe was hulle God en die hele familie het Hom gedien. Dalk was die hoogte op Gibeon die plek waar die Saulfamilie byeengekom en Jahwe aanbid het. En toe Saul koning geword het, was dit net 'n logiese stap om Jahwe, sy familie se God, tot alleen-God te verhef ${ }^{24}$. 
Met die verdeling van die ryk (ca $920 \mathrm{vC}$ ) het groot godsdiensveranderinge plaasgevind. Godsdiens se maatskaplike waarde het gedurende hierdie periode weer eens duidelik geblyk: dit is die krag wat 'n samelewing bymekaar kan hou, dit bind mense en formuleer gesamentlike doelwitte, dit formuleer waardes wat sin aan mense se lewens verskaf, dit is 'n onmisbare element in enige gemeenskap ${ }^{25}$. Elke politieke party en staatsmag het godsdiens dus ten diepste nodig. Dit is 'n politieke middel om orde in die staat te skep. Jerobeam I het dit ook terdeë besef. Met sy bewindsaanvaarding het hy 'n ingrypende godsdiensbeleid gevolg. Hy het "twee goue kalwerbeelde laat maak"; "die een beeld (is) in Bet-El opgestel en die ander in Dan"; hulle het "selfs die een beeld na Dan toe begelei". Jerobeam I het hierdie beelde toe aan Jahwe verbind: "hier is nou die beelde van julle God wat julle uit Egipte laat wegtrek het". Verder het hy "heiligdomme op die hoogtes gebou en hy het mense uit die volk wat nie priesters was nie, as priesters aangestel". Jerobeam I het ook die kultiese kalender verander en "op die vyftiende dag van die agste maand 'n fees gehou net soos die fees in Juda" (1 Kon 12:28-32). Hiervoor sou die Deuteronomis hom nooit vergeef nie en hy sou die simbool van sondige opstand teen Jahwe verteenwoordig. In die Koningsboek word voortdurend na die sonde van Jerobeam, die seun, van Nebat verwys ${ }^{26}$.

Wat Jerobeam I gedoen het, kan egter ook in 'n ander lig verstaan word. In 'n sekere sin kon hy ook nie anders nie. As monarg moes hy in die religeuse behoeftes van sy volk voorsien. Dit was tog onmoontlik vir Israel om in Jerusalem, die hoofstad van 'n ander ryk en 'n ander teologie, te gaan aanbid. Indien hy dit sou toelaat, sou hy sy plig as koning verwaarloos het. Jerobeam I moes self voorsien en dit het hy ook gedoen. Uiteraard het politieke motiewe 'n beslissende rol gespeel en is godsdiens vir die bestendiging van die staat gebruik. Al die politiekery het egter die geloof in Jahwe ten goede gestrek. Jerobeam I kon vir 'n vorm van politeïsme gekies het, maar het dit nie gedoen nie. Jahwe was die God van die staat Israel. En alhoewel dit in politieke begrippe vertolk is, het dit die geloof in Jahwe bevoordeel.

\section{DIE UITTOG BEGROND DIE STAAT}

Geen staat kan sonder 'n begrondingsmite nie. Politieke oortuigings, beleid en optrede roep om mitologiese (filosofiese of religieuse) begronding. Dít het Jerobeam I geweet. Hy het 'n mite nodig gehad wat die bestaan van sy 
koninkryk sou legitimeer. 'n Ondersteuningsmite wat sin aan sy politieke optrede sou verleen. Interessant is dat hy toe die uittogverhaal as stigtingsverhaal ("national charter myth") van die Noordryk kies. Deur hierdie verhaal sou die stigting van die nuwe jong staat in die noorde begrond en ondersteun word. Deur die verhaal van Israel se slawerny in Egipte, die bevryding, die deurtog, die omswerwinge in die woestyn sou die burgers van die staat Israel bymekaar gebring en tot een gemaak word. Moses sou in die proses die hooffiguur word rondom wie eindelose verhale sou ontstaan 27.

Politieke optrede het dus tot die vorming en uitbouing van die uittogtradisie aanleiding gegee. Politieke belange het die uittoggebeure tot stigtingsverhaal gemaak. Politieke nood het die uittog tot 'n onontbeerlike geloofsoortuiging laat word. Politieke legitimering het die noorderlinge 'n teologiese bril verskaf waarvolgens die wêreld verstaan kon word. Mettertyd het die uittog ook 'n onherroeplik deel van die Noordrykteologie geword. Priesters soos die Leviete, "(which) constituted a faction of the religious personnel of the Israelite state cult", was nou aan hierdie teologie verbonde ${ }^{28}$. Al was die Leviete deel van 'n bepaalde staatsopset wat die samelewing geheel en al deursuur het, was hulle ywer vir Jahwe, die God van die uittoggebeure, goed bekend ${ }^{29}$. Dieselfde kan van Elia en Elisa gesê word. Hulle was hart en siel aan die uittogtradisie verbonde. Wat vir die staat 'n strakke politieke beleid was, was vir hierdie manne 'n lewende werklikheid $^{30}$. Hosea was ook in die uittogtradisie gedrenk. Volgens hom het die Jahwe-godsdiens in die smeltkroes van Egipte ontstaan. Gedurende die woestyntyd is Jahwe se nabyheid intens ervaar en het Israel geleer om op Hom te vertrou en na sy wil te leef. Vir Hosea was die uittog- en die woestynteologie dus die "geloofsartikels" waarvolgens die volk moes geleef het ${ }^{31}$. Dalk het die uittogtradisie en die Mosesfiguur Jerobeam I se politieke sug na 'n geskikte stigtingsverhaal juis nodig gehad. Sonder daardie politiek kon hierdie teologie dalk nie so geblom het nie.

\section{STAATSINGRYPE MAAK JAHWE EN EL EEN}

Tussen staatsgodsdiens en familiegodsdiens was daar voortdurende spanning. Soos alle Ou-Nabye-Oosterse vorste was die Israelitiese konings ook vir familiegodsdiens bang. Tydens die beoefening van die familiegodsdiens op verafgeleë gebiede is woorde gespreek en rites uitgevoer wat dalk teen die staat gemik was. Waarskynlik was die plattelanders ook meer tot 'n anti-koning-houding geneig. Samuel het op 'n keer uiters negatief oor die konings se outokratiese en gewelddadige optrede gepraat. Volgens hom 
sou die konings "julle seuns vat en party by sy wa en sy perderuiters aanstel, party om voor sy wa uit te hardloop, party sal hy aanstel as bevelvoerders ... party om sy lande te ploeg en sy oes in te samel ... julle dogters sal hy vat om vir hom salf te meng, om vir hom te kook en te bak; julle beste lande, wingerde en olyfboorde sal hy vat en aan sy amptenare gee" (1 Sam 8:11-17). Waarskynlik reflekteer Samuel die vyandige gesindheid van 'n groot aantal Israeliete. Dit is te verstane dat negatiewe dinge oor die staat ook by die familiegodsdiens gesê kon gewees het.

Dié situasie het net tot groter staatsinmenging aanleiding gegee. Priesters is by kultusplekke aangestel om van alle opstand berig te doen. 'n Goeie voorbeeld van hierdie priesterspioene was Amasia. Toe hy Amos se kritiese woorde gehoor het, het hy dit onmiddellik aan Jerobeam II gerapporteer: "Amos is besig om hier in Israel 'n komplot teen u te smee. Die land kan dit nie uithou met alles wat hy sê nie" (Amos 7:10-17).

'n Ander vorm van beheer, was die akkommodasie en die integrasie van die familiegodsdiens by die staatsgodsdiens. Miskien die belangrikste voorbeeld is die integrasie van Jahwe en El. Soos reeds gesê, was Elaanbidding ' $n$ integrale deel van die vroeg-Israelitiese familiegodsdiens. El (en Baäl) is deur verskillende familiegroepe by verskillende plaaslike aanbid. Plek-plek het hierdie aanbidding tot teenstand en selfs opstand teen die konings gelei. Uiteraard was die staat hiervan bewus. En om groter beheer oor die familiegodsdiens te verkry, is met 'n stelselmatige proses begin om $\mathrm{El}$ met Jahwe te identifiseer. Kalwerbeelde het die god $\mathrm{El}$ gesimboliseer en dié is veral in Bet-El aanbid. Interessant is Jerobeam I se woorde ná die oprigting: " $(\mathrm{H})$ ier is nou die beelde van julle God wat julle uit Egipte laat wegtrek het" (1 Kon 12:28). Hiermee is Jahwe en El met mekaar geïdentifiseer. Duidelik blyk dit ook uit die Kuntillet "Arjud"inskripsie waarin na "Jahwe van Samaria en sy Asjera" verwys word. Hiervolgens het 'n noue koppeling tussen "Jahwe van Samaria" en "Asjera van Samaria” bestaan. In die Ugaritiese mitologie was Asjera egter EI se gesellin en Jahwe het hom klaarblyklik verdring. Volkome identifikasie het plaasgevind en Jahwe het die plek van $\mathrm{El}$ langs Asjera ingeneem ${ }^{32}$.

Outoritêre staatsoptrede het dus aan die einde van die tiende eeu tot 'n ander Godsbeskouing aanleiding gegee. Deur die staat se selfsugtige politieke optrede het 'n nuwe konsep van Jahwe ontstaan. Dit sou ook die staatspolitiek dien: "As is so often the case in the history of religions, the proclamation of a new dogma (in the present case the equation of El with Yahweh) served political interests" ${ }^{33}$. En die vraag is of alles so sleg was. Uiteraard het die staat sy mag hierdeur uitgebrei, maar dit het ook religieuse konsekwensies ingehou: die Jahwe-geloof is teologies geweldig 
verbreed. Deur die inkorporering van elemente uit die El-aanbidding by die Jahwe-geloof en die identifikasie van $\mathrm{El}$ met Jahwe het laasgenoemde se mag ongelooflik uitgebrei. Jahwe was nou nie net meer die God van die staat nie, maar het ook mag oor die familie (en alles wat daarmee verband hou) gehad. En kon dit sonder staatsinmenging gebeur het?

\section{JAHWE-EL EN BAäL IS NIE GELYK NIE!}

Bogenoemde vereniging van Jahwe en El het ook mettertyd spanning geskep. Baäl het nog as 't ware buite gestaan. Die Jahwe-El-volgelinge was die ware Israel en die Baälmense buitestaanders. Ten tye van die Omriede 'n groot verandering egter ingetree. Hulle was verligte leiers wat Israel 'n moderne staat wou maak. In hierdie doel het hulle ook geslaag. Deur middel van 'n verligte buitelandse beleid is die bande met Fenisië, Juda en ander state stewig gesmee. Vir die religieuse spanning is toe ook 'n verligte, dinamiese plan bedink: die gelykstelling van Jahwe-El en Baäl. Identifisering tussen Jahwe-El en Baäl was net nie moontlik nie. Vir die Jahwe-El-gelowige was die Baälgodsdiens afstootlik en van integrasie was daar geen sprake nie.

Gelyke beregtiging van Jahwe-El en Baäl was die enigste moontlikheid. In die amptelike godsdiens het Baäl toe 'n gelyke plek met Jahwe-El gedeel. 'n Baältempel is in Samaria opgerig, talle kultusplekke het oor die hele land tot stand gekom en 'n groot aantal kultiese personeel is aangestel. Verder moes die priesters van Jahwe-El 'n klomp voorregte of opoffer of met die Baälpriesters deel. Hierdie institusionalisering van die Baälgodsdiens was 'n uitstekende politieke stap om die spanninge te besweer en die mag te versterk ${ }^{34}$.

Hierdie stap het tot 'n opstand aanleiding gegee wat die ganse geloof van Israel radikaal gevorm het. 'n Fundamentalistiese Jahwe-alleenbeweging het ontstaan. Dit was 'n streng beweging wat geen kompromie geduld het nie. In hierdie maalkolk van die Omriede se religieuse en politieke kragte is ' $n$ verdere gestalte aan 'n bepaalde Jahwe-geloof gegee: Hy is één, het mag oor die natuur, is jaloers, ensovoorts. Verder het die profete die ware aard van die koningsmag begin ontdek en al hoe meer krities teenoor die staat begin word. Slegs binne hierdie smeltkroes kon die Jahwe-geloof hierdie spesifieke gestalte aangeneem het. 


\section{SLOT}

a. Tot 'n groot mate het die Christendom hom van sy historiese milieu vervreem en historiese denke op die agtergrond geplaas. Dikwels het dit tot teologiese geheueverlies gelei. Ons het geen innige verbondenheid met die verlede meer nie en ons ken nie die gemeenskap met die heiliges van alle eeue nie. Dalk help godsdiensgeskiedenis ons weer om die historiese band met die talle geloofsgetuies van alle eeue te versterk.

b. Dalk beleef ons nog 'n "herlewing" van godsdiensgeskiedenis en 'n "vermindering" van teologieë van die Ou Testament. So iets sou versoberend op die Ou-Testamentiese wetenskap inwerk. Aan die einde van die twintigste eeu moet die vak "Teologie van die Ou Testament" opnuut weer kritieks bekyk word. 'n Indringende ondersoek na die probleme en beperkinge van hierdie dissipline is baie nodig. Miskien moet die verhouding tussen 'n teologie en 'n godsdiensgeskiedenis ook weer hergedefineer word ${ }^{35}$ : "Perhaps a theology of the Old Testament will accomplish more if it redefines itself in terms of history and establish a firmer link with 'Religionsgeschichte'" 36 .

c. In Suid-Afrika is die band tussen godsdiens en politiek nog altyd onderskat. Daar word gemeen dat die kerk 'n bepalende politieke faktor is en dat die Bybel politieke aanwysings vir 'n gelukkige reënboognasie kan verskaf. Dit is nie waar nie. Soos altyd word die kerk ook nou weer deur die politiek vir staatsdoelwitte (waarheid, versoening, geregtigheid) gebruik. Dalk hou dit korttermyn voordele in, maar op die lange duur kan dit gevaarlik wees ${ }^{37}$.

\section{NOTAS:}

$1 \quad \mathrm{~K}$ van der Toorn, Family religion in Babylonia, Syria and Israel: continuity and change in the forms of religious life, Leiden 1996.

$2 \quad$ Van der Toorn, $a w, 234$.

3 Van der Toorn, $a w, 225$.

4 G A Anderson, "Hebrew religion" in: H H Rowley (ed), The Old Testament and modern study, London 1967, 283-310; P D Miller, "Israelite religion" in: D Knight \& G M Tucker, The Hebrew Bible and its modern interpreter's, Philadelphia 1985, 210-237.

5 J H le Roux, "Our historical heritage", OTE 10/3 (1997), 410-423.

6 R Albertz, Religionsgeschichte Israels in alttestamentlicher Zeit, Göttingen $1992,39$.

7 M Schoeman, "Kritiek en die krisis van representasie”, Fragmente 1/1 (1998), 95-103. 
R G Collingwood, The idea of history, Oxford 1994, 137.

9 D Goosen, "Verlies, rou en affirmasie. Dekonstruksie en die gebeure", Fragmente 1/1 (1998), 54-79.

10 J Degenaar, "Deconstruction - the celebration of language" in: B Lategan (ed), The reader and beyond, Pretoria 1992, 187-212; J P H Wessels, Die agtergeblewe nasies in die land. 'n Teologiese ondersoek in Rigters 2:2-3:6, Pretoria 1993, 62-67.

11 Van der Toom, $a w, 184-194$.

12 Van der Toorn, $a w, 206-235$.

13 Van der Toorn, $a w, 242-246$.

14 J C de Moor, The rise of Yahwism, Leuven 1990, 13-34.

15 De Moor, $a w, 32$.

16 Van der Toorn, $a w, 238$.

$17 \quad$ Van der Toorn, $a w, 241$.

18 Van der Toorn, $a w, 255-265$.

19 Van der Toorn, $a w, 261$.

20 Van der Toom, $a w, 281-283$.

21 H H Rowley, From Joseph to Joshua, London 1970, 153-163.

22 Van der Toorn, $a w, 282-285$.

23 Van der Toorn, $a w, 268$.

24 Van der Toorn, $a w, 266-286$.

25 Kuitert, Alles is politiek, maar politiek is niet alles, Baarn 1985, 54-73.

26 Van der Toorn, $a w, 287-291$.

27 Van der Toorn, $a w, 286-291$.

28 Van der Toorn, $a w, 305$.

29 Van der Toorn, $a w, 302-306$.

30 Van der Toorn, $a w, 306-315$.

$31 \quad$ Van der Toorn, $a w, 297-298$.

$32 \quad$ Van der Toorn, $a w, 320-328$.

33 Van der Toorn, $a w, 328$.

$34 \quad$ Van der Toorn, $a w, 328-338$.

35 O Eissfeldt, "Religionsgeschichte und Alttestamentliche Theologie", ZAW 44 (1926), 1-12.

36 J H le Roux, $a w, 1997,420$.

37 J H le Roux, "Politieke mag, die Ou Testament en kerkeenheid", Skrif en Kerk 17(2) 1996, 359-372. 